\title{
MUSEUM SENI KARAWITAN BALI DI GIANYAR
}

\author{
I Kadek Oka Sumantara \\ Program Studi Arsitektur Fakultas Teknik Universitas Ngurah Rai \\ akunoka90@gmail.com \\ Ayu Putu Parthami Lestari \\ Program Studi Arsitektur Fakultas Teknik Universitas Ngurah Rai \\ utari.parthami@unr.ac.id \\ Ngakan Putu Ngurah Nityasa \\ Program Studi Arsitektur Fakultas Teknik Universitas Ngurah Rai \\ ngurah.nityasa@unr.ac.id
}

\begin{abstract}
Abstrak
Seni karawitan adalah seni suara yang disajikan menggunakan sistem notasi, warna suara, ritem yang memiliki fungsi dan sifat nada mempunyai aturan dalam sajian instrumental dan vokal. Karawitan adalah kesenian yang sudah menjadi bagian dari kebudayaan dan kehidupan sehari-hari masyarakat di Bali. Dikatakan tidak ada upacara besar keagamaan yang selesai tanpa ikut sertanya karawitan. Begitu luhur nilai-nilai yang terdapat dalam seni karawitan Bali, sehingga perlu dilakukan pelestarian dengan pengadaan wadah untuk mengumpulkan kesenian, meningkatkan minat generasi muda dan masyarakat, sebagai dokumentasi sejarah serta perkembangan seni budaya Bali. Di Kabupaten Gianyar berpotensi untuk dibangun museum seni karawitan Bali karena berbagai faktor, seperti tingginya seni gamelan, masyarakat sebagian besar pengerajin ukir dan dikenalnya tokoh seniman karawitan yaitu Prof. Dr. I Made Bandem, MA. dan Prof. Dr. I Wayan Dibia, SST, MA disana. Konsep dasar pada museum seni karawitan Bali di Gianyar ini adalah Preservatif, Edukatif dan Rekreatif. Juga didukung dengan tema arsitektur Neo Vernakular sebagai upaya mewujudkan Gianyar sebagai kota budaya sehingga dapat mempertahankan ciri khas setempat. Di museum seni karawitan Bali terdapat bangunan utama (area pameran tetap dan panggung tertutup) serta bangunan penunjang (workshop, artshop dan cafe). Total luas ruangan pada adalah $10.191 \mathrm{~m} 2$ dengan site seluas 12.737 m2. Museum terletak di Jalan Raya Samu, Singapadu Kaler, Sukawati Gianyar. Melalui program ruang dan program tapak kemudian ditentukan konsep perancangan. Konsep perancangan terdiri dari konsep site, konsep bangunan, konsep struktur dan konsep utilitas. Keseluruhan konsep perancangan juga berdasarkan atas konsep dasar dan tema rancangan sebagai acuan dasar dalam mendesain bangunan museum seni karawitan Bali.
\end{abstract}

Kata Kunci: Seni Karawitan Bali, Preservatif, Edukatif dan Rekreatif, Neo Vernakular

\begin{abstract}
Karawitan art is the art of sound presented using a notation system, sound color, rhythm which has a function and tone properties that have rules in instrumental and vocal offerings. Karawitan is an art that has become part of the culture and daily life of people in Bali. It is said that no major religious ceremony is completed without the participation of musicals. The values contained in the Balinese musical arts is so noble, so that preservation is necessary by procuring a forum for gathering, increasing the interest of the young generation and the community, as a documentation of the history and development of Balinese cultural arts. In Gianyar there are the potential to build a Balinese musical art museum, such as the high level of gamelan, the community, most of which are carving craftsmen and the well-known figures of musical artists, namely Prof. Dr. I Made Bandem, MA. and Prof. Dr. I Wayan Dibia, SST, MA. The basic concept of the Balinese musical art museum in Gianyar is Preservative, Educative and Recreational. With the support of the Neo Vernacular architectural theme as an effort to make Gianyar a city of culture so that it can maintain its local characteristics. In the Balinese karawitan art museum, there is a main building (permanent exhibition area and closed stage) as well as supporting buildings (workshops, art shops and cafes). The total area of space is 10,191 m2 with site area of 12,737 m2. The museum is located on Jalan Raya Samu, Singapadu Kaler, Sukawati Gianyar. Through the architectural and site program then the design concept is determined. The design concept consists of site, building, structural and utility
\end{abstract}


concepts. The overall design concept is also based on the concept and design theme as basic reference in designing Balinese musical art museum.

Keywords: Balinese Karawitan Arts, Preservative, Educative and Recreational, Neo Vernacular

\section{PENDAHULUAN}

\section{Latar Belakang}

Kesenian merupakan bagian kebudayaan yang hidup subur di Bali. Tata kehidupan masyarakat yang sebagian besar penduduknya beragama Hindu ini selalu dipenuhi oleh upacara-upacara keagamaan seperti Dewa Yadnya, Rsi Yadnya, Butha Yadnya, Manusa Yadnya, dan Pitra Yadnya. Pada setiap upacara keagamaan ini kesenian seperti tari dan karawitan memegang peranan penting, bahkan dikatakan tidak ada upacara besar keagamaan yang selesai tanpa tari dan karawitan.

Kebudayaan memiliki nilai budaya yang luhur, universal dan tetap ada sepanjang jaman. Seni karawitan Bali mencerminkan budaya dari lakon cerita dan cara kesenian tersebut dibawakan. Kata karawitan berasal dari suku kata "rawit" yang artinya kecil, rumit, dan indah (Aryasa Putra, 2014). Seni karawitan adalah seni suara yang disajikan menggunakan sistem notasi, warna suara, ritem yang memiliki fungsi dan sifat nada, dengan aturan dalam sajian instrumental dan vokal. Pada periode tahun 1970 sampai dengan 1990an, seni karawitan Bali mengalami kemajuan yang mengembirakan. Minat seni karawitan Bali pada waktu itu memperlihatkan sisi yang menarik perhatian dan menentukan masa depan seni karawitan. Bahkan terjadi penyebaran gamelan ke seluruh Bali, hingga keluar daerah (Surabaya, Yogyakarta, Bandung dan Jakarta) serta keluar negeri. Di tingkat Internasional, gamelan Bali (gong kebyar, semar pegulingan, dan gender wayang) sudah tersebar ke Eropa, Jerman, Australia, Jepang, Canada, India, dan terbanyak ke Amerika Serikat.Kondisi ini diikuti oleh munculnya komposisi-komposisi karawitan baru yang semakin rumit dengan teknik permainan yang semakin kompleks.

Kabupaten Gianyar merupakan salah satu kabupaten di Provinsi Bali dan juga merupakan kawasan dengan beraneka ragam potensi pariwisata yang sangat menawan dan dikenal sebagai daerah seni. Jumlah penduduk Kabupaten Gianyar pada tahun 2015 mencapai 495.100 jiwa. Diproyeksikan penduduk Kabupaten Gianyar akan meningkat setiap tahun yang akan berdampak pada meningkatnya generasi muda dengan potensi dan jiwa seni. Di Gianyar sendiri juga ada tokoh seniman karawitan yang terkenal yaitu Prof. Dr. I Made Bandem, MA. dan Prof. Dr. I Wayan Dibia, SST, MA.

Letak kabupaten Gianyar di tengah pulau Bali mendukung berdirinya museum seni karawitan Bali sehingga dapat dengan mudah mengumpulkan data mengenai seni karawitan yang tersebar di seluruh pulau. Museum ini akan dapat menawarkan suasana tenang bagi wisatawan yang mungkin sudah penat dengan hiruk pikuk aktivitas di pusat kota Gianyar. Museum dirancang memadukan unsur komersil dan rekreatif dengan tetap memanfaatkan potensi yang ada di kabupaten Gianyar. Museum tidak hanya sebagai tempat memamerkan gamelan, tempat pementasan seni karawitan saja tetapi juga sebagai tempat memproduksi gamelan. 


\section{Rumusan Masalah}

Dari latar belakang di atas dapat dirumuskan beberapa permasalahan diantaranya :

a. Bagaimana konsep fungsional Museum Seni Karawitan Bali di Gianyar ?

b. Bagaimana konsep dasar dan tema perancangan Museum Seni Karawitan Bali di Gianyar?

\section{KAJIAN PUSTAKA}

Museum adalah suatu lembaga yang tetap diusahakan untuk kepentingan umum dalam memelihara, menyelidiki serta memamerkan benda-benda kepada masyarakat umum, guna penikmatan dan pendidikan (Nantra, 1990). Berdasarkan c, museum adalah lembaga tempat penyimpanan, perawatan, pengamanan dan pemaanfaatan benda-benda bukti materiil hasil budaya manusia guna menunjang upaya perlindungan dan pelestarian kekayaan budaya bangsa. Sedangkan menurut Internasional Council of Museum (2008), museum adalah sebuah lembaga yang bersifat tetap, tidak mencari keuntungan, melayani masyarakat, perkembangannya, merawat, menghubungkan untuk tujuan studi, pendidikan dan rekreasi. Museum memiliki tugas menyimpan, merawat, mengamankan dan memanfaatkan koleksi museum berupa benda cagar budaya. Dengan demikian museum memiliki dua fungsi besar yaitu : sebagai tempat pelestarian dan sebagai sumber informasi, museum melaksanakan kegiatan pemaanfaatan melalui penelitian dan penyajian.

\section{METODE}

Di bawah disampaikan metode penelitian yang dimanfaatkan dalam perancangan Museum Seni Karawitan Bali di Gianyar.

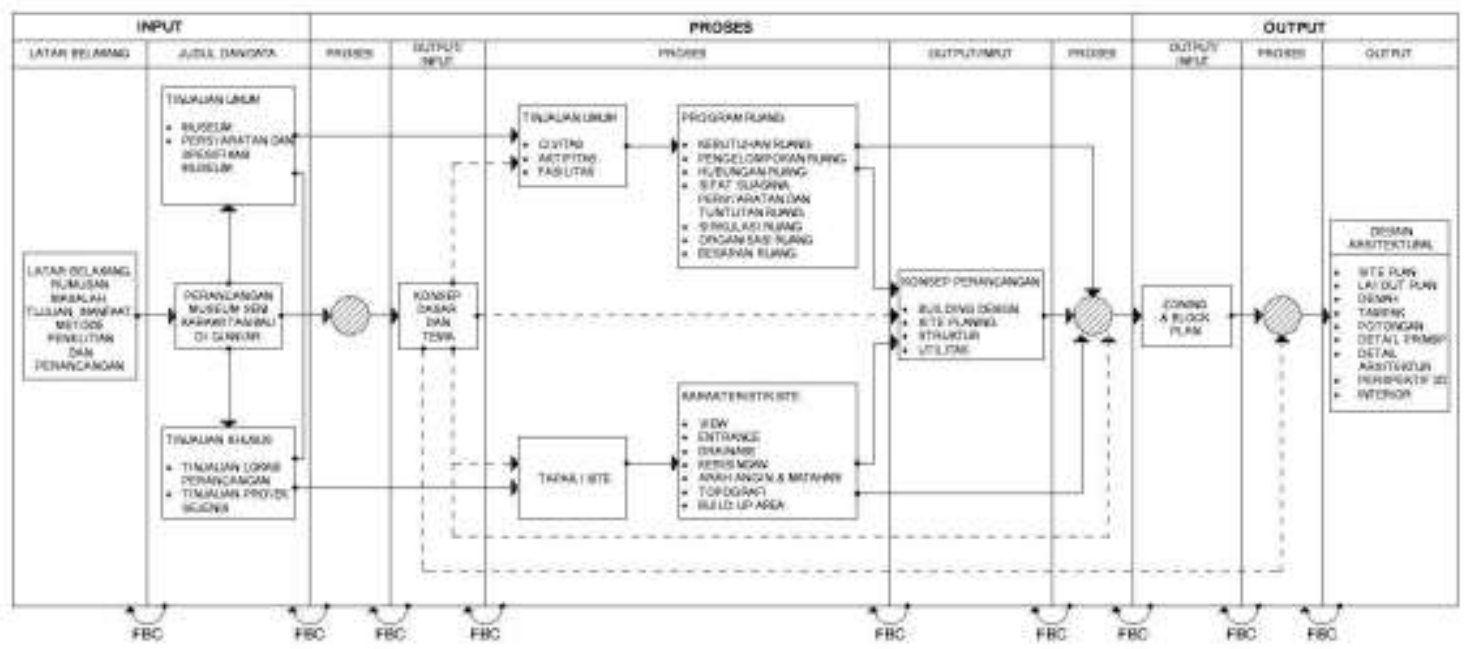

Gambar 1. Metode Penelitian

Sumber: Sumantara, 2020 


\section{HASIL DAN PEMBAHASAN}

\section{Pelaku Kegiatan}

Pelaku kegiatan pada Museum Seni Karawitan Bali di Gianyar dibagi menjadi 2 yaitu pengunjung dan pengelola. Jumlah pengunjung diprediksi sebanyak 118 orang/ hari dan jumlah pengelola 117 orang.

\section{Jenis Ruang}

Berikut adalah kebutuhan ruang Museum Seni Karawitan Bali di Gianyar.

Tabel 1. Jenis Ruang Museum Seni Karawitan di Bali

\begin{tabular}{|c|c|c|}
\hline No & Jenis Ruang & Nama Ruang \\
\hline \multirow[t]{4}{*}{1.} & \multirow[t]{4}{*}{ Ruang Pelayanan Pameran } & R. Pameran Tetap \\
\hline & & R. Pameran Temporer \\
\hline & & R. Pertunjukan Dalam \\
\hline & & R. Pertunjukan Luar \\
\hline \multirow[t]{7}{*}{2.} & \multirow[t]{7}{*}{ Ruang Pelayanan Umum } & Lobby \\
\hline & & Counter Informasi \\
\hline & & Counter keamanan \\
\hline & & Loket Karcis \\
\hline & & Toilet \\
\hline & & Café \\
\hline & & Artshop \\
\hline \multirow[t]{11}{*}{3.} & \multirow[t]{11}{*}{ R. Pelayanan Adminsitrasi } & R. Kepala Museum \\
\hline & & R. Tamu \\
\hline & & R. Kepala Tata Usaha \\
\hline & & R. Kepala Teknis Koleksi \\
\hline & & R. Kepala Konservasi \\
\hline & & R. Kepala Bimbingan Edukasi \\
\hline & & R. Kepala Pertunjukan \\
\hline & & R. Kepala Café \\
\hline & & R. Kepala Pelatihan Gamelan \\
\hline & & R. Kepala Artshop \\
\hline & & R. Kepala Workshop \\
\hline \multirow[t]{2}{*}{4.} & \multirow[t]{2}{*}{ R. Pelayanan Bimbingan } & R. Perpustakaan \\
\hline & & R. Seminar \\
\hline \multirow[t]{5}{*}{5.} & \multirow[t]{5}{*}{ R. Pelayanan Teknis } & R. Penerimaan Koleksi \\
\hline & & R. Sortir Koleksi \\
\hline & & R. Dokumentasi \\
\hline & & R. Laboratorium \\
\hline & & R. Penyimpanan \\
\hline \multirow[t]{6}{*}{6.} & \multirow[t]{6}{*}{ R. Penunjang } & R. Pelatihan \\
\hline & & R. Workshop \\
\hline & & Parkir \\
\hline & & R. M\&E \\
\hline & & Pos Satpam \\
\hline & & Tempat Suci \\
\hline
\end{tabular}

Sumber: Sumantara, 2020 


\section{Karakteristik Site}

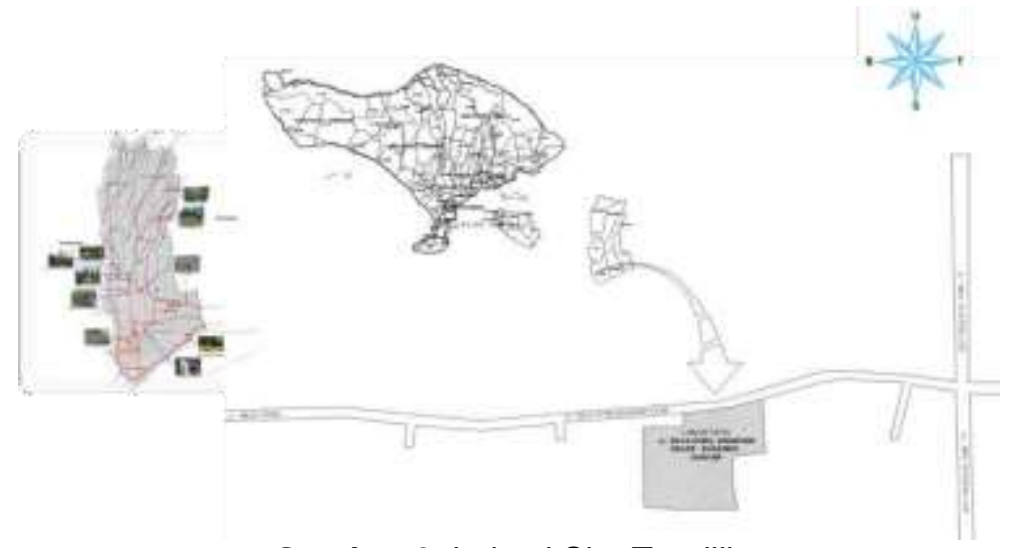

Gambar 2. Lokasi Site Terpilih

Sumber: Sumantara, 2020

Luas site yang diperlukan dalam perancangan Museum Seni Karawitan Bali di Gianyar adalah 12.737 m2. Site terpilih berlokasi di Jalan Raya Samu, Singapadu Kaler, Sukawati, Gianyar dengan luas 17,875 m2.

\section{Spesifikasi Museum Seni Karawitan Bali di Gianyar}

Museum Seni Karawitan Bali di Gianyar adalah tempat memamerkan gamelan, tempat pementasan seni karawitan dan juga tempat memproduksi gamelan. Museum seni karawitan Bali ini berfungsi sebagai sarana pengetahuan sekaligus rekreatif bagi wisatawan serta dilengkapi dengan fasilitas penunjang workshop, artshop dan cafe.

\section{Konsep Dasar Rancangan}

Konsep dasar dari Museum Seni Karawitan Bali di Gianyar ini adalah Preservatif, Edukatif dan Rekreatif. Dalam hal ini dapat dilihat unsur yang paling mendasar atau hakekat dari museum adalah pelestarian, perlindungan dan pendidikan atau preservatif dan edukatif. Sedangkan Rekreatif disini maksudnya adalah cara menanamkan fungsi pendidikan. Sesuai dengan pengertian tersebut, maka museum ini bertujuan untuk mengumpulkan dan mengamankan warisan budaya bernilai luhur yang berupa seni gamelan karawitan Bali.

\section{Tema Rancangan}

Tema yang akan dipergunakan dalam perencanaan dan perancangan Museum Seni Karawitan Bali di Gianyar adalah Neo Vernakular. Tema perancangan diaplikasikan pada tampak bangunan, seperti contohnya pada gambar di bawah ini. 


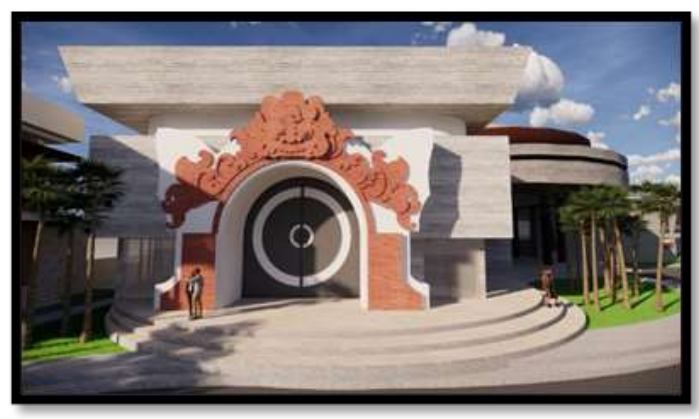

Gambar 3. Tampak Bangunan Utama Sumber : Hasil olah data, 2020

\section{Konsep Perancangan Tapak}

Konsep perancangan tapak terdiri dari, konsep entrance, pola sirkulasi, ruang luar, pola parkir dan konsep zoning site. Konsep entrance pada Museum Seni Karawitan Bali di Gianyar ini dibuat dengan dua akses keluar masuk yang berbeda, dengan didesain lebih masuk ke dalam site bertujuan untuk memberikan ruang untuk sirkulasi kendaraan dan memberikan rasa nyaman dan aman bagi seluruh civitas. Pada konsep pola sirkulasi yang dipilih adalah gabungan dari sirkulasi radial dikarenakan bangunan yang bersifat kompleks dan memerlukan kemudahan dalam menjangkau setiap fasilitas. Ruang luar pada Museum Seni Karawitan Bali di Gianyar ini berupa parkir, taman, dan area pejalan kaki. Untuk konsep pola parkir yang diterapkan terdiri dari dua alternatif parkir yaitu pola lurus sudut $90^{\circ}$ dan pola parkir dengan sudut $60^{\circ}$ untuk lebih memaksimalkan fungsi lahan.

\section{Konsep Perancangan Bangunan}

1. Konsep Massa. Pola massa yang diterapkan adalah pola massa terklaster, yang terdiri atas beberapa bentuk massa bangunan yang terpisah namun memiliki satu kesatuan fungsional, mengikuti bentuk site tanah, dengan membuat satu bangunan utama sebagai ikon museum ini dengan bangunan-bangunan penunjang di sekitar bangunan utama.

2. Konsep Penampilan Bangunan. Konsep entrance bangunan utama museum menggunakan langgam arsitektur Bali dengan bentuk seperti gambelan gangsa, dengan pintu berbentuk bulat seperti gong gamelan, dengan finishing tempelan batu bata merah dan paras putih.

\section{Konsep Perancangan Struktur}

Sistem struktur yang digunakan dalam perancangan Museum Seni Karawitan Bali di Gianyar adalah bor pile pada sub struktur, sistem rangka dengan modul struktur pada super struktur dan rangka ruang dengan menggunakan material baja pada upper struktur.

\section{Konsep Perancangan Utilitas}

a. Sistem Sirkulasi dan Transportasi 
Sirkulasi pada fungsi pelayanan umum menggunakan sirkulasi radial. Sedangkan pada ruang pameran menggunakan sirkulasi linear. Sedangkan pada sirkulasi vertikal menggunakan tangga.

b. Sumber Distribusi Tenaga Listrik

Sumber tegangan listrik diperoleh dari jaringan listrik PLN yang tersedia di sekitar tapak dan untuk tenaga cadangannya akan dibantu oleh genset dengan sistem ACOS.

c. Sistem Pencahayaan

Sistem pencahayaan, dibagi menjadi dua yaitu pencahayaan alami dan buatan. Ruangan yang menggunakan pencahayaan alami seperti café, tempat pelatihan gamelan, workshop, artshop. Sedangkan ruangan yang menggunakan pecahayaan buatan adalah ruang pemeran.

d. Sistem Penghawaan

Bangunan ini menggunakan dua sistem yaitu penghawaan alami dan penghawaan buatan. Di museum ini penghawaan alami digunakan untuk ruangan cafe, workshop, artshop dan ruang pelatihan gamelan. Sedangkan untuk penghawaan buatan digunakan untuk ruangan pemeran koleksi gamelan, dan ruang pertunjukan dalam.

e. Penangkal Petir

Sistem penangkal petir yang dipergunakan adalah sistem penangkal petir dengan jenis franklin.

f. Sistem Keamanan

Sistem keamanan yang digunakan di museum ini adalah Moveable camera dan Fixed camera. Moveable camera adalah kamera yang dapat bergerak sedangkan Fixed camera adalah kamera yang menggunakan lensa cembung yang mampu merekam ruangan secara keseluruhan.

g. Pemadam Kebakaran

Sistem pemadam kebakaran di museum ini menggunakan sistem Fires Extinguisher, Fire Alarm, Sprinkler dan hydrant.

h. Sistem Air Bersih dan Air Kotor

Sistem distribusi air bersih memakai sistem tangki tekan, sumber air dari jaringan PDAM dan sumur bor yang disalurkan ke bak penampungan kemudian dipompa ke tangki tekan dan dari tangki tekan disalurkan ke masing - masing ruang yang membutuhkan.

i. Sistem Pengolahan Sampah

Air kotor dari WC pembuangan langsung ke septictank kemudian ke sumur peresapan, air bekas dari KM, diolah dalam STP sebelum dialirkan ke riol kota, sedangkan air buangan dari dapur cafe dibuatkan perangkap lemak baru kemudian diolah dalam STP dan selanjutnya disalurkan ke riol kota. Diameter pipa pembuangan untuk saluran panjang minimal 50-100mm dan kemiringan pipa 1/50-1/100 agar saluran lancar dan efisien. 


\section{Desain Perancangan Arsitektur}

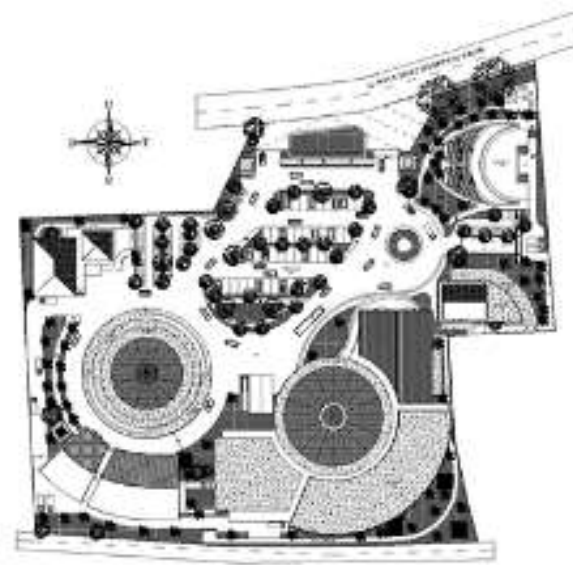

Gambar 4. Site Plan

Sumber: Sumantara, 2020

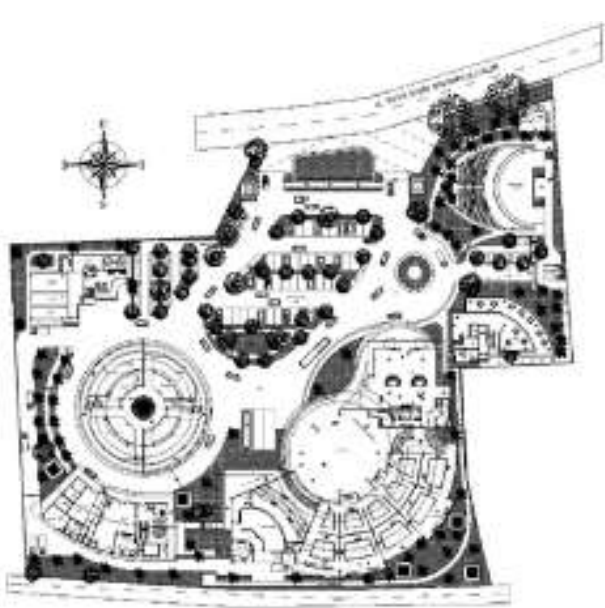

Gambar 5. Layout Plan

Sumber: Sumantara, 2020

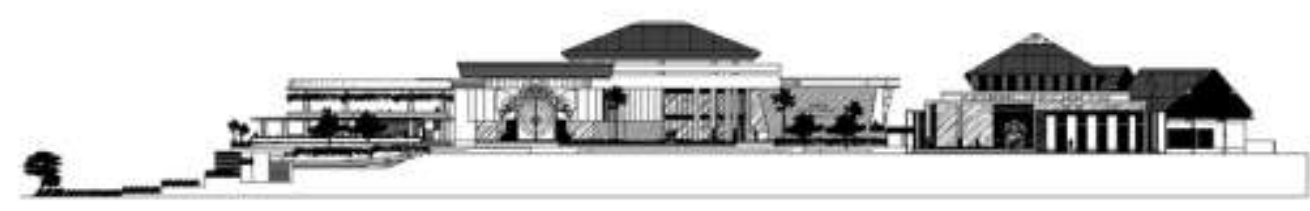

Gambar 6. Tampak Depan Site

Sumber: Sumantara, 2020

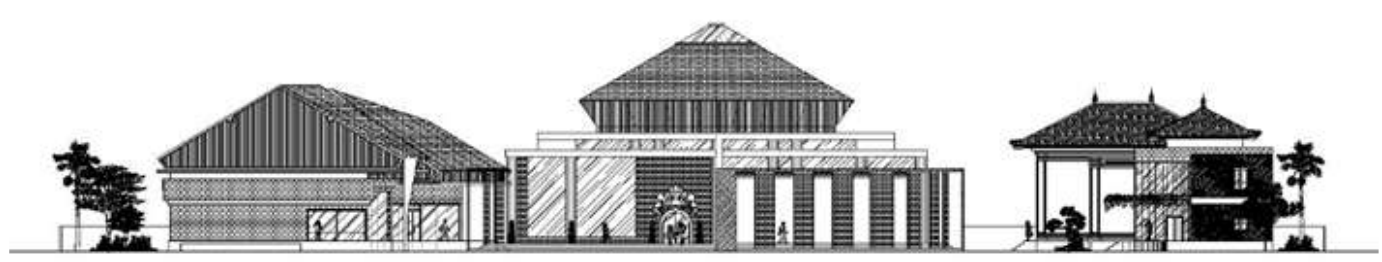

Gambar 7. Tampak Samping Site

Sumber: Sumantara, 2020 


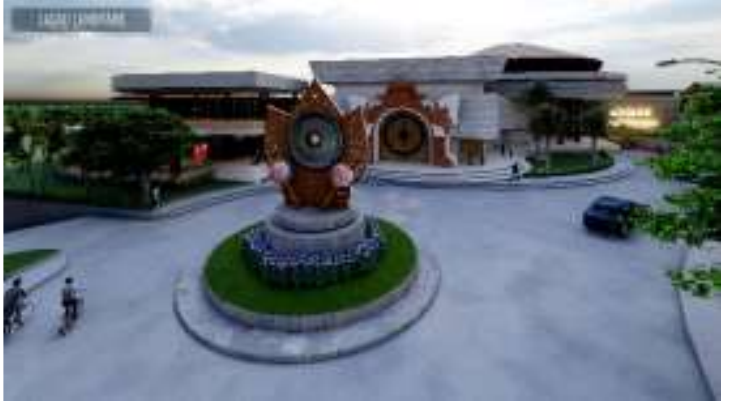

Gambar 8. Fasade Landmark Sumber: Sumantara, 2020

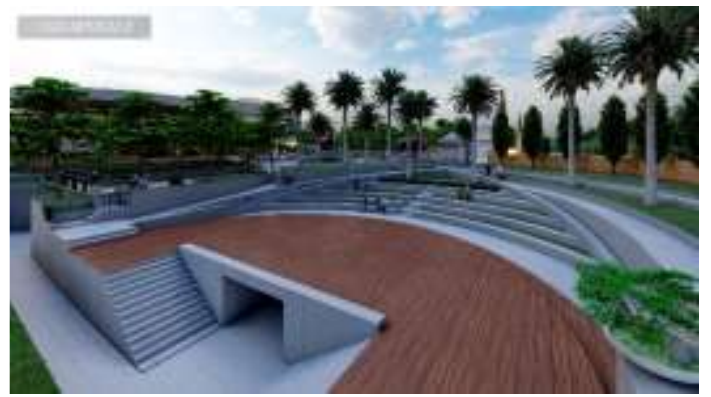

Gambar 10. Fasade Amplitheatre Sumber: Sumantara, 2020

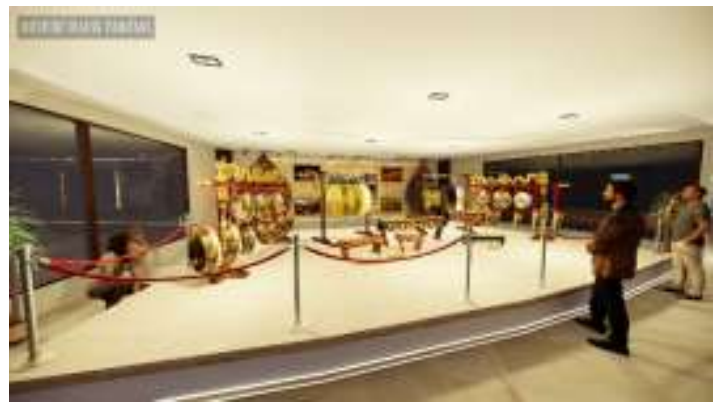

Gambar 12. Interior Ruang Pameran Sumber: Sumantara, 2020

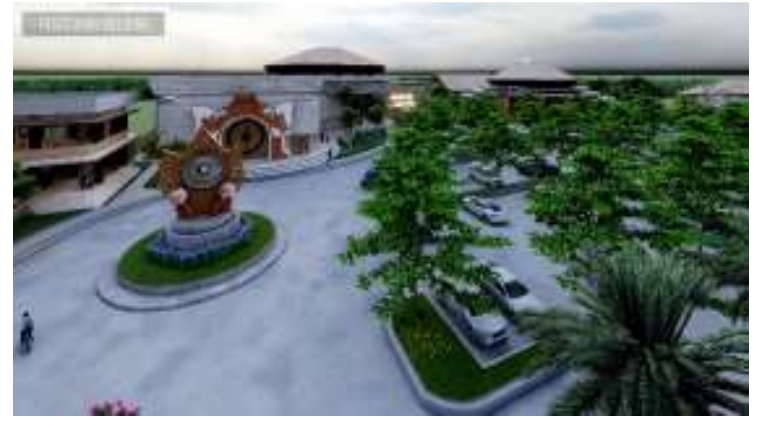

Gambar 9. Bangunan Utama Sumber: Sumantara, 2020

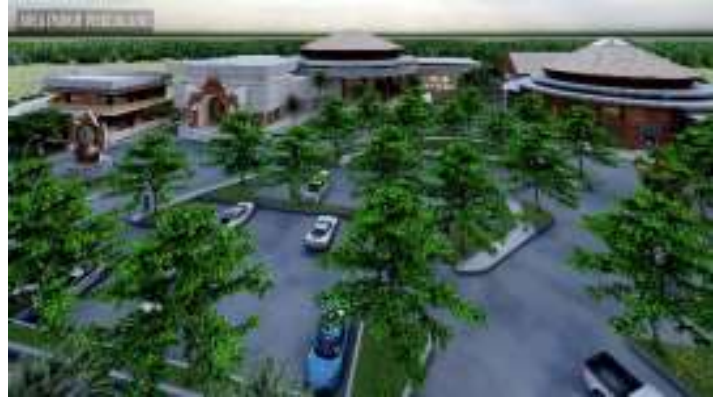

Gambar 11. Area Parkir Pengunjung Sumber: Sumantara, 2020

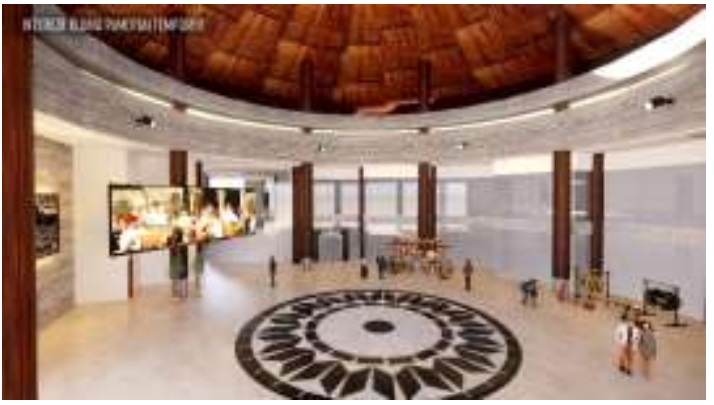

Gambar 13. Interior Ruang Pameran Temporer Sumber: Sumantara, 2020

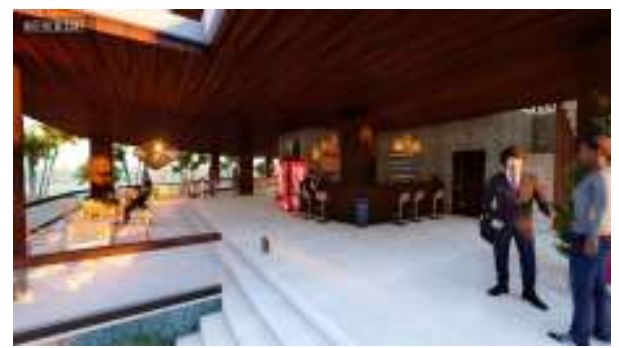

Gambar 14. Interior Cafe

Sumber: Sumantara, 2020 


\section{PENUTUP}

\section{Simpulan}

Dari paparan di atas, didapat kesimpulan sebagai berikut:

a. Konsep fungsional Museum Seni Karawitan Bali di Gianyar adalah sbb

Tabel 2. Konsep Fungsional Museum Seni Karawitan di Gianyar

\begin{tabular}{|c|c|c|c|}
\hline \multirow{6}{*}{$\frac{\text { No }}{1 .}$} & \multicolumn{2}{|c|}{ Konsep Fungsional } & \multirow{2}{*}{$\begin{array}{l}\text { Kesimpulan } \\
\text { - Akses entrance terdiri dari } 2 \text { (exit dan in) } \\
\text { - Bentuk entrance terinspirasi dari gamelan Bali }\end{array}$} \\
\hline & \multirow{5}{*}{$\begin{array}{l}\text { Konsep } \\
\text { Perancangan } \\
\text { Tapak }\end{array}$} & Entrance & \\
\hline & & Parkir & $\begin{array}{l}\text { Pola parkir yang paling banyak dimanfaatkan adalah parkir } \\
\text { lurus }\end{array}$ \\
\hline & & Ruang Luar & $\begin{array}{l}\text { - Peracangan akan diperkuat dengan elemen-elemen ruang } \\
\text { luar seperti tanaman baik sebagai peneduh maupun } \\
\text { penanda, elemen buatan seperti patung, dll. }\end{array}$ \\
\hline & & Sirkulasi & $\begin{array}{l}\text { - Sirkulasi pengunjung dibuat dengan sirkulasi bercabang } \\
\text { atau radial } \\
\text { - Sirkulasi pengelola dibuat dengan sirkulasi linear yang } \\
\text { beralur ke semua fasilitas }\end{array}$ \\
\hline & & Zoning & $\begin{array}{l}\text { - Tapak berada di selatan jalan yang merupakan sumber } \\
\text { penerimaan pengunjung dan pengelola. Di tengah tapak } \\
\text { akan dibuat parkir, di timur tapak akan dibuatkan cafe, } \\
\text { pertunjukan luar karena view. Di selatan tapak akan dibuat } \\
\text { bangunan utama untuk pameran koleksi dan di barat } \\
\text { tapak akan dibuat bangunan pengelola. } \\
\text { - Ruang publik diutamakan berada di bagian utara. }\end{array}$ \\
\hline \multirow[t]{3}{*}{2.} & \multirow[t]{3}{*}{$\begin{array}{l}\text { Konsep } \\
\text { Perancangan } \\
\text { Bangunan }\end{array}$} & Zoning & $\begin{array}{l}\text { - Zoning Bangunan Utama: Ruang Pertunjukan dalam, } \\
\text { Lobby. Ruang Pameran Temporer, Ruang Pameran } \\
\text { Tetap, dan Taman } \\
\text { - Zoning bangunan artshop dan workshop: Area Pengerajin, } \\
\text { Area Penjualan, Gudang, dan area drop off } \\
\text { - Zoning Bangunan Pelatihan: Area Pelatihan, Ruang } \\
\text { Genset, dan Gudang } \\
\text { - Zoning Bangunan Café: Dapur, area tempat makan, } \\
\text { dapur, KM/WC } \\
\text { - Zoning bangunan pelayanan teknis dan pengelola } \\
\text { adminstrasi lantai 1: Ruang tamu, Laboratorium, Ruang } \\
\text { penerimaan, sortir, dan pencatatan koleksi } \\
\text { - Zoning bangunan pelayanan teknis dan pengelola } \\
\text { adminstrasi lantai 2: Ruang Kepala museum, ruang staff } \\
\text { dan ruang rapat }\end{array}$ \\
\hline & & $\begin{array}{l}\text { Bentuk dan } \\
\text { Pola Massa }\end{array}$ & $\begin{array}{l}\text { Bentuk pola massa di museum adalah compound, dengan } \\
\text { membuat satu bangunan utama dengan bangunan-bangunan } \\
\text { penunjang di sekitarnya. }\end{array}$ \\
\hline & & Tampilan & $\begin{array}{l}\text { Konsep entrance bangunan utama museum yang } \\
\text { menggunakan langgam arsitektur Bali dipadukan dengan } \\
\text { bentuk seperti gambelan gangsa, dengan pintu berbentuk } \\
\text { bulat seperti gong gamelan. Dengan finishing tempelan batu } \\
\text { bata merah dan paras putih. }\end{array}$ \\
\hline \multirow[t]{2}{*}{3.} & \multirow[t]{2}{*}{$\begin{array}{l}\text { Konsep } \\
\text { Struktur } \\
\text { Bangunan }\end{array}$} & Substruktur & $\begin{array}{l}\text { - pondasi yang akan digunakan adalah pondasi Mini Pile } \\
\text { dengan penampang segi tiga dan telapak untuk bangunan } \\
\text { utama. Untuk bangunan pendukung menggunakan } \\
\text { pondasi menerus }\end{array}$ \\
\hline & & Super & Bahan struktur yang digunakan adalah baja atau beton \\
\hline
\end{tabular}




\begin{tabular}{|c|c|c|c|}
\hline & & Struktur & bertulang sebagai sistem balok dan kolom. \\
\hline & & $\begin{array}{l}\text { Upper } \\
\text { Struktur }\end{array}$ & $\begin{array}{l}\text { - Sistem struktur pada bangunan pameran menggunakan } \\
\text { struktur rangka dengan material baja profil } U \text {. } \\
\text { - Sistem struktur pada bangunan komersial menggunakan } \\
\text { struktur rangka dengan material kayu, yaitu atap akan } \\
\text { dibuat expose yang mampu menjadi daya tarik atau } \\
\text { estetika. }\end{array}$ \\
\hline \multirow[t]{8}{*}{4.} & \multirow{8}{*}{$\begin{array}{l}\text { Konsep } \\
\text { Utilitas } \\
\text { Bangunan }\end{array}$} & Listrik & $\begin{array}{l}\text { Sumber listrik diperoleh dari jaringan listrik PLN dan tenaga } \\
\text { cadangan dari genset dengan sistem ACOS. }\end{array}$ \\
\hline & & Pencahayaan & $\begin{array}{l}\text { Ruangan yang menggunakan pencahayaan alami adalah } \\
\text { bangunan penunjang seperti café, tempat pelatihan gamelan, } \\
\text { workshop, artshop. Sedangkan ruangan yang menggunakan } \\
\text { pencahayaan buatan adalah ruang pameran. }\end{array}$ \\
\hline & & Penghawaan & $\begin{array}{l}\text { Sistem penghawaan yang digunakan adalah penghawaan } \\
\text { alami dengan jendela, ventilasi dan panel. Penghawaan } \\
\text { buatan menggunakan } A C \text { Split dan cerobong asap atau } \\
\text { Exhaust Fan untuk membantu mengeluarkan udara didalam } \\
\text { ruangan terutama untuk ruang pameran/museum }\end{array}$ \\
\hline & & $\begin{array}{l}\text { Penangkal } \\
\text { Petir }\end{array}$ & Jenis franklin aktif. \\
\hline & & $\begin{array}{l}\text { Sistem } \\
\text { Pemadam } \\
\text { Kebakaran }\end{array}$ & $\begin{array}{l}\text { Menggunakan } 4 \text { sistem yaitu Fires Extinguisher, Fire Alarm, } \\
\text { Sprinkler dan hydrant. }\end{array}$ \\
\hline & & $\begin{array}{l}\text { Sistem } \\
\text { Keamanan }\end{array}$ & $\begin{array}{l}\text { Sistem keamanan yang digunakan di museum ini adalah } \\
\text { Moveable camera dan Fixed camera. }\end{array}$ \\
\hline & & $\begin{array}{l}\text { Sistem Air } \\
\text { Bersih }\end{array}$ & $\begin{array}{l}\text { Sistem distribusi air bersih memakai sistem tangki tekan, } \\
\text { sumber air dari jaringan PDAM dan sumur bor yang } \\
\text { disalurkan ke bak penampungan kemudian dipompa ke } \\
\text { tangki tekan. }\end{array}$ \\
\hline & & $\begin{array}{l}\text { Sistem Air } \\
\text { Kotor }\end{array}$ & $\begin{array}{l}\text { Air kotor dari WC ke septictank kemudian ke sumur } \\
\text { peresapan. Air bekas KM, diolah dalam STP sebelum } \\
\text { dialirkan ke riol kota. Sedangkan air buangan dari dapur kafe } \\
\text { dibuatkan perangkap lemak kemudian diproses dalam STP } \\
\text { dan selanjutnya disalurkan ke riol kota. }\end{array}$ \\
\hline
\end{tabular}

Sumber: Analisis Data, 2020

b. Konsep dasar perancangan Museum Seni Karawitan Bali di Gianyar adalah Preservatif, Edukatif dan Rekreatif. Sedangkan tema perancangan Museum Seni Karawitan Bali di Gianyar adalah Neo Vernakular.

\section{Saran}

Begitu luhur nilai-nilai yang terdapat dalam seni karawitan Bali, sehingga perlu dilakukan pelestarian, pengadaan wadah untuk mengumpulkan kesenian tersebut, meningkatkan minat generasi muda dan masyarakat. Museum juga berfungsi sebagai dokumentasi sejarah dan perkembangan seni budaya Bali. Serta cermin tingkat peradaban masyarakat Bali agar nilai-nilai budayanya tetap lestari dan tetap dalam kehidupan umat manusia bahkan untuk masa yang akan datang.

\section{DAFTAR PUSTAKA}

\section{Peraturan Perundangan}

Peraturan Pemerintah RI No. 19 Tahun 1995. Pengertian Museum 
Badan, Buku, Jurnal, dan Internet :

Aryasa Putra, 2014. Pengertian Karawitan Bali. http://blog.isidps.ac.id/putraaryasa/karawitan-bali,_Diakses 29/04/2019

Departemen Pendidikan dan Kebudayaan Tahun 1988. Klasifikasi Museum dan Penyajian Koleksi Museum.

Internasional Council Of Museum Tahun 2008. Pengertian Museum dan Fungsi Museum.

Nantra Putu, Pemanfaatan Museum-museum di Bali sebagai Sumber Belajar oleh masyarakat Bali (Denpasar : 1990)

Internasional Cauncil Of Museum Tahun 2008. Pengertian Museum dan Fungsi Museum.

Sumantara, I Kadek Oka, 2020. Museum Seni Karawitan Bali di Gianyar. Prodi Arsitektur Fakultas Teknik Universitas Ngurah Rai. Skripsi. Tidak diterbitkan. 